\title{
Phases of Infection and Gene Expression of Fusarium graminearum During Crown Rot Disease of Wheat
}

\author{
Amber E. Stephens, ${ }^{1,2}$ Donald M. Gardiner, ${ }^{1}$ Rosemary G. White, ${ }^{3}$ Alan L. Munn, ${ }^{2}$ and John M. Manners ${ }^{1}$ \\ ${ }^{1}$ CSIRO Plant Industry, Queensland Bioscience Precinct, 306 Carmody Road, St. Lucia, Brisbane, QLD 4067, Australia; \\ ${ }^{2}$ The Institute for Molecular Bioscience, The University of Queensland, St Lucia, QLD, 4072, Australia ${ }^{3}$ CSIRO Plant Industry, \\ PO Box 1600, Canberra ACT 2601, Australia
}

Submitted 13 June 2008. Accepted 20 August 2008.

\begin{abstract}
Fusarium graminearum causes head blight (FHB) and crown rot $(\mathrm{CR})$ diseases in wheat. Compared with FHB, CR symptom development occurs slowly, usually taking 4 to 8 weeks to become visible. To characterize CR development, we used histological and real-time quantitative polymerase chain reaction analyses to assess fungal colonization during a timecourse of infection. Three distinct phases of infection were identified: i) initial spore germination with formation of a superficial hyphal mat at the inoculation point, ii) colonization of the adaxial epidermis of the outer leaf sheath and mycelial growth from the inoculation point to the crown, concomitant with a drop in fungal biomass, and iii) extensive colonization of the internal crown tissue. Fungal gene expression was examined during each phase using Affymetrix GeneChips. In total, 1,839 $F$. graminearum genes were significantly upregulated, including some known FHB virulence genes (e.g., TRI5 and TRI14), and 2,649 genes were significantly downregulated in planta compared with axenically cultured mycelia. Global comparisons of fungal gene expression with published data for FHB showed significant similarities between early stages of FHB and CR. These results indicate that CR disease development involves distinct phases of colonization, each of which is associated with a different fungal gene expression program.
\end{abstract}

Additional keywords: deoxynivalenol, DON, pathogenicity.

The filamentous fungus Fusarium graminearum Schwabe (teleomorph Gibberella zeae [Schw.] Petch) is one of the most important pathogens of small grain cereals. It is best known as the pathogen responsible for Fusarium head blight (FHB) disease of wheat, also referred to as head scab (Goswami and Kistler 2004). Infection of wheat heads by $F$. graminearum reduces grain yield by degrading starch granules in the kernels (Jackowiak et al. 2005). It also reduces the quality of the grain by contaminating it with harmful mycotoxins such as the trichothecene deoxynivalenol (DON),

Current address for A. L. Munn: School of Medical Science, Griffith University (Gold Coast campus), Southport, QLD 4222, Australia.

Corresponding author: A. E. Stephens: E-mail: amber.stephens@csiro.au; Telephone: +61-7-3214 2632; Fax: +61-7-3214 2920.

* The $e$-Xtra logo stands for "electronic extra" and indicates that one supplementary figure and two supplementary tables are published online. rendering it unsafe for human and livestock consumption. Because of the global importance of FHB disease, F. graminearum has been intensively researched. Its genome has been sequenced (Cuomo et al. 2007), and functional genomics tools have been developed, including the Affymetrix GeneChip for gene expression profiling (Guldener et al. 2006b). Mutant collections for specific genes and gene clusters also exist, but there are currently only around 26 published genes that have been shown to encode $F$. graminearum pathogenicity and virulence factors. Three of these genes (TRI5, TRII4, and TRI6) are in the well-recognized gene cluster that encodes for trichothecene production (Dyer et al. 2005; McDonald et al. 2005; Proctor et al. 1997). As expected, signaling pathways have also been shown to play a role in $F$. graminearum pathogenicity on wheat heads. One mitogenactivated protein kinase (MAPK) encoding gene, MGV1 (Hou et al. 2002), was shown to be a virulence factor involved in female fertility during $F$. graminearum sexual reproduction. Another MAPK gene, MAP1 (GPMK1) (Jenczmionka et al. 2003; Urban et al. 2003), is essential for pathogenicity and is also involved in the development of perithecia and ascospores. Considering that the plant pathogenic fungus Magnaporthe oryzae has over 200 pathogenicity loci (Jeon et al. 2007), it is likely that the journey to understanding $F$. graminearum pathogenicity is only just beginning.

In addition to $F$. graminearum, there are several other $F u$ sarium species that cause Fusarium crown rot (CR) disease of wheat, such as $F$. pseudograminearum. In this study, $F$. graminearum was chosen as a model Fusarium pathogen for $\mathrm{CR}$ disease because of the extensive genomic resources available. In contrast to FHB, CR disease affects the stem base and crown of wheat plants (Mudge et al. 2006), producing necrotic lesions in these tissues. Like FHB, CR can decrease grain yield by up to $100 \%$ in Australia (Southwell et al. 2003) and 35 to $61 \%$ in North America (Smiley et al. 2005), and there is emerging evidence that CR disease may lead to contamination of wheat stubble and heads with the mycotoxin DON (Mudge et al. 2006). It is thought that the principal inoculum for CR comes from the infested stubble of the preceding year, and this can remain viable for up to two years (Burgess 2005). Through the growing season, the wheat stem base would come in physical contact with the stubble and this could facilitate the initial infection process. Farming practices such as crop rotation can decrease the severity of Fusarium diseases in wheat, but it is the consensus of the grains industry that the production of new CR-resistant wheat cultivars is highly desirable to reduce the crop losses 
due to this disease. In order for this to happen, a greater understanding of the molecular interactions between the host and the pathogen is required, including the potential mechanisms involved in fungal pathogenicity and virulence.

Fungal colonization of wheat inflorescences and the associated fungal gene-expression profiles and proteomics for $F$. graminearum have been studied extensively in regard to the development of FHB disease (Guldener et al. 2006b; Kruger et al. 2002; Paper et al. 2007; Trail et al. 2003), but there is little information available about CR disease development. It has been shown that genes necessary for the biosynthesis of trichothecenes, e.g., TRI5, are expressed during stem infection and that, at late stages of infection of mature plants, the central stem lumen and surrounding parenchyma are extensively colonized by the fungus (Mudge et al. 2006). That study also demonstrated that disease symptoms and fungal growth appear to develop much more slowly during CR disease than FHB disease. In the present study, we report on a systematic investigation of the colonization process, using real-time quantitative polymerase chain reaction ( $\mathrm{qPCR}$ ) to estimate fungal DNA as an indirect measure of fungal biomass during infection. Three distinct phases of colonization were identified. This was followed by histological analysis of the infection process and gene expression profiling of the fungus in planta in each the three phases of infection. CR disease appears to develop in a temporally and spatially coordinated program of colonization, and the expression of fungal genes associated with specific infection stages has been observed.

\section{RESULTS}

Fungal biomass assays indicate that there are three phases of disease development during CR infection of wheat.

To investigate the CR infection process and how it relates to the slow development of CR symptoms, a timecourse of infection was carried out. Fungal biomass of $F$. graminearum was estimated as CR disease developed from the time of inoculation up to 49 days postinoculation (dpi), when symptom expression was apparent. Plant crown and stem (leaf sheath) tissue was sampled from the germinated seed to leaf 1 . Real-time qPCR amplification of the DNA sequence for $F$. graminearum $18 \mathrm{~S}$ rRNA relative to the wheat actin-binding protein DNA sequence was performed, using extracted genomic DNA from inoculated stems to estimate changes in the $F$. graminearum biomass during CR disease development (Fig. 1). This revealed three distinct phases in the colonization of wheat stem bases by $F$. graminearum. Phase 1 was a significant increase in relative fungal biomass from 0 dpi to at least 2 dpi. Phase 2 was a statistically significant decrease in fungal biomass. Finally, phase 3 was a statistically significant increase in relative biomass from 14 to $35 \mathrm{dpi}$, including a slow increase from 14 to $28 \mathrm{dpi}$ followed by a rapid increase between 28 and 35 dpi, eventually reaching a plateau. An independent experiment gave similar results when fungal biomass was estimated by reverse transcriptase (RT)-qPCR of extracted total RNA amplifying the same genes but with fewer timepoints (data not shown).

Microscopic analysis of fungal colonization of wheat stems.

To further investigate the three phases of infection described above, we performed histological analysis of $F$. graminearum during CR infection. Hand sections of inoculated shoot tissue from fresh seedlings were taken at 2, 14, and 35 dpi, representing each of the three phases. Fungal tissue was visualized by staining with either the Alexa Fluor 488 conjugate of wheat germ agglutinin (WGA) that binds to lectin in fungal cell walls or with toluidine blue (Fig. 2).

At $2 \mathrm{dpi}$, the spores had germinated at the inoculation site, with germ tubes and superficial hyphae extending across the leaf-sheath surface. At this stage, there seemed to be no directional growth of germ tubes up or down the sheath, although growth around and up the trichomes was frequently observed (Fig. 2A and B).

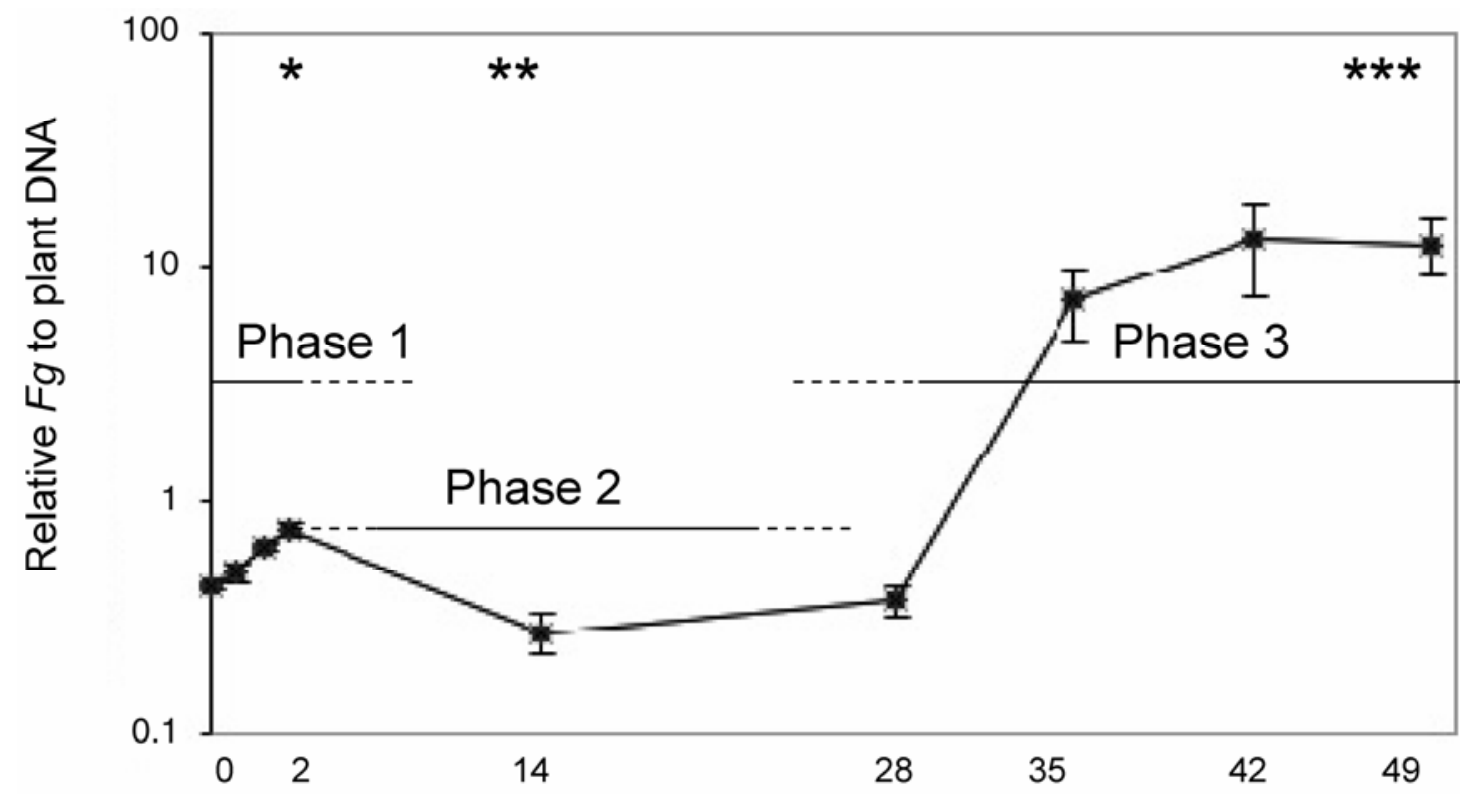

\section{Days postinoculation}

Fig. 1. Graph showing relative Fusarium graminearum biomass during crown rot of wheat. Fungal biomass relative to that of wheat was measured by assaying fungal 18S rDNA and wheat actin binding protein sequences by quantitative real-time polymerase chain reaction using extracted DNA as a template. All error bars are the standard error of the mean for three independent replicates. $t$-tests showed statistically significant changes in fungal biomass between the three phases. $*$ indicates $P$ value $=0.009$ between 0 and 2 days postinoculation $(\mathrm{dpi}) ; *, P$ value $=0.008$ between 2 and 14 dpi; and $* * *, P$ value $=0.038$ between 14 and 49 dpi. 
At 14 dpi, there was no evidence of mycelium at the point of inoculation. Confocal microscopy analysis confirmed the presence of $F$. graminearum hyphae inside the cells of the inner adaxial epidermis of the first leaf sheath, indicating that penetration had occurred. Interestingly, $F$. graminearum had only colonized the first leaf sheath and was growing below the point of inoculation, and most fungal colonization was observed at the base of the sheath, below the soil surface (Fig. 2C and D). At this stage, there was no visible necrotic lesion formation at the stem base.

At $35 \mathrm{dpi}$, extensive $F$. graminearum colonization was observed in the vascular tissue and pith of the crown (Fig. 2E). It appears that colonization of the interior of the wheat stem occurs at the crown after fungal colonization of the outer leaf sheath and migrates down to the base of the leaf sheath. As shown in Figure 2F, visible macroscopic symptoms started to appear at the crown of the wheat plant during this phase of colonization with the plant tissue directly surrounding the $F$. graminearum infection site becoming dark and necrotic.

\section{Analysis of global $\boldsymbol{F}$. graminearum gene expression during infection relative to cultured mycelium.}

Analysis of fungal development described above indicates that $F$. graminearum has three distinct phases of infection. We were thus interested in examining whether there is differential gene expression in the fungus associated with each phase.

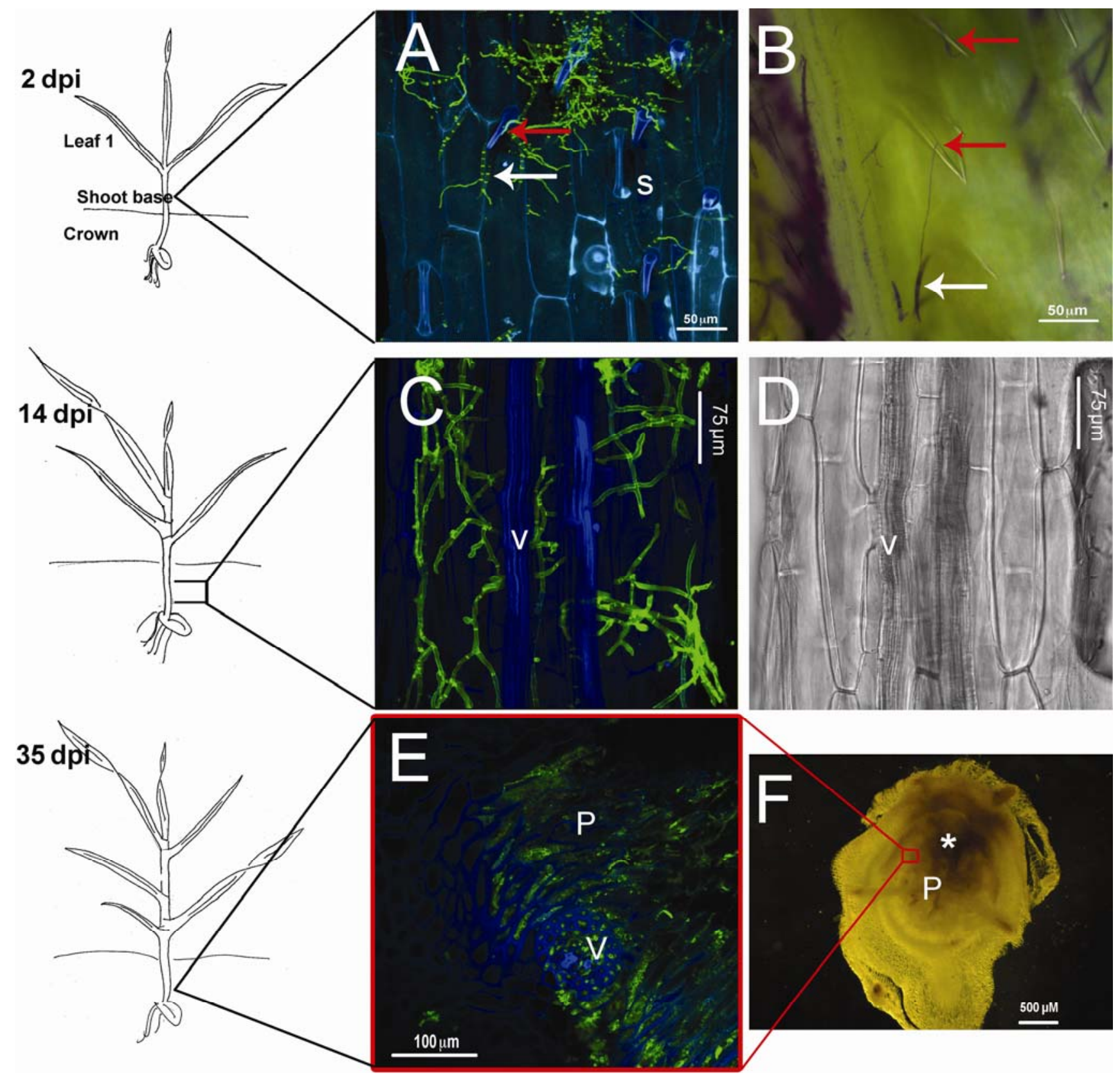

Fig. 2. Infection phases of Fusarium graminearum during crown rot of wheat. Plants were inoculated at the base of the shoot and sectioned by hand to visualize the extent of colonization at 2, 14, and 35 days postinoculation. A and $\mathbf{B}$, Germinating spores on the leaf-sheath surface at the point of inoculation, white arrows indicate $F$. graminearum spores and red arrows show germ tube interaction with trichomes as a laser scan confocal image (A) and a bright field image stained with toluidine blue (B). C and D, Inner surface of leaf sheath $1 F$. graminearum hyphae are inside epidermal cells, viewed in a confocal image (C) and a bright field view of the same field with no staining (D). E, Confocal image of transverse section of crown showing established colonization of pith (p) and secondary axial (v) bundles. F, The bright field view of the same sample as shown in E but with no staining and under less magnification; pith (p) tissue shows necrosis around the infection, center of infection is shown with an asterisk $(*)$. 
Global $F$. graminearum gene expression in planta and in vitro was analyzed using the Fusarium Affymetrix GeneChip (Guldener et al. 2006b). For in planta samples, wheat seedlings were inoculated with $F$. graminearum at the shoot base, and total RNA was obtained at 2, 14, and 35 dpi to correspond with phases 1, 2, and 3, respectively, of the infection process. Each timepoint consisted of at least three biological replicates taken in parallel, and each biological replicate was a pool of 18 stem bases. In order to tentatively identify $F$. graminearum genes that had been differentially expressed during growth in planta compared with axenic culture conditions, total RNA was extracted from a sample of $F$. graminearum cultured in complete defined media. This sample consisted of four biological replicates taken in parallel. Raw GeneChip data can be found in the PLEXdb database as experiment FG12.

Using GeneSpring GX 7.3 analysis software, probe sets (for convenience, hereafter termed genes) were filtered for significantly higher and lower expression levels in at least one of the three in planta timepoints $(2,14$, or $35 \mathrm{dpi})$ compared with the in vitro samples (Fig. 3). The robust multiarray analysis (RMA) was used for a per chip normalization to the median to allow cross-array comparisons. In total, 1,839 genes were found to give significantly higher expression signals in planta, and 2,649 genes exhibited significantly lower signals in planta. RT-qPCR analysis of 16 genes confirmed the accuracy of GeneChip expression results; 13 of the 16 genes displayed very similar gene expression profiles between the PCR and GeneChip experiments (Supplementary Figure 1 contains data for gene names and results). Differences between the two analysis meth- ods for three genes were at the 35-dpi stage, at which variation in expression was at its greatest. The majority of genes showing higher or lower expression in planta as compared with cultured mycelium were identified from the 2 and 14 dpi timepoints, suggesting that these early stages of CR may be critical for the ability of $F$. graminearum to successfully colonize the plant. The actual numbers of genes that showed higher or lower expression during growth in infected wheat at specific and combined infection stages are illustrated in Figure 3.

Functional classes of genes expressed in planta.

Genes showing significantly different expression in planta as compared with in vitro (up- or downregulated) were grouped according to the Munich Information Center for Protein Sequences (MIPS) FunCatDB classification of gene products from the $F$. graminearum genome (Fig. 4 ) and were compared with the genome as a whole to obtain a $P$ value. This $P$ value was used to identify which functional classes of genes were statistically significantly enriched within a list of genes. While some differentially expressed genes had potential roles identified, based on significant sequence homology to known genes, many of the genes found were of unknown function. Of the genes upregulated in planta, a significantly larger portion $(59 \%, P$ value $\cong 0$ ) were unclassified with respect to putative function, whereas only $25 \%$ ( $P$ value $\cong 1)$ of the genes showed lower expression and were unclassified, suggesting our understanding of the cellular processes occurring during infection is very limited.

Functional categories that were enriched in upregulated (Table 1) and downregulated (Supplementary Table 1) genes in

\section{A Genes with significantly higher expression in planta}

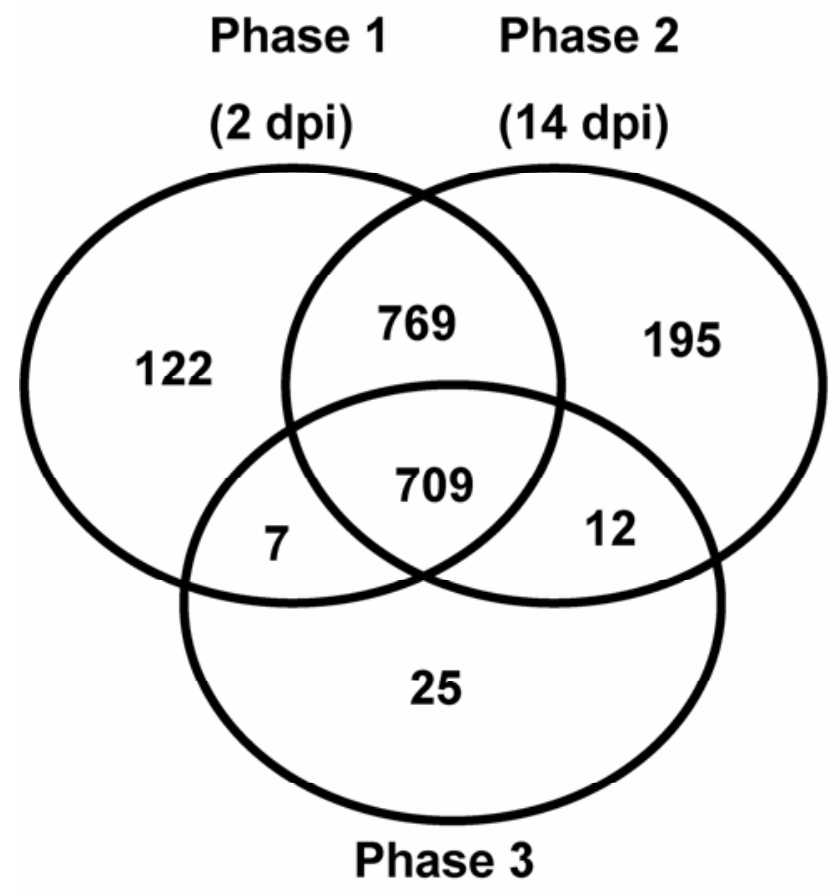

(35 dpi)

\section{B Genes with significantly lower expression in planta}

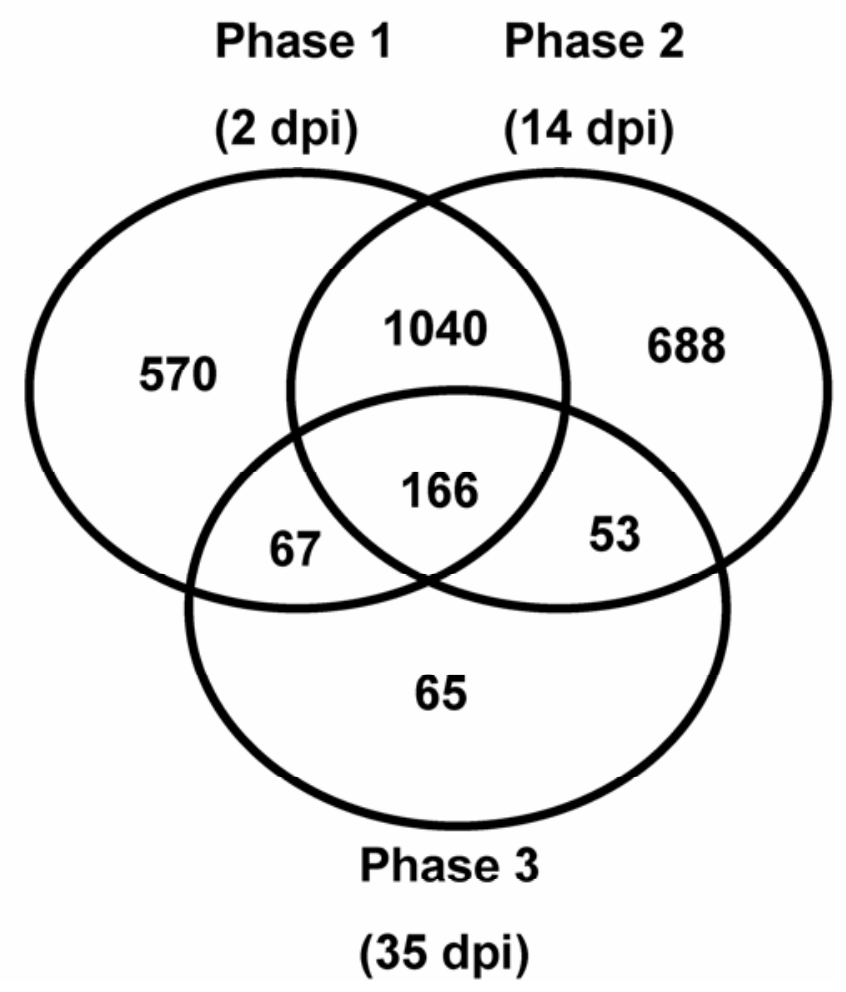

Fig. 3. Venn diagram showing the number of Fusarium graminearum genes with $\mathbf{A}$, higher and $\mathbf{B}$, lower expression during the three phases of crown rot infection $(2,14$, and 35 days postinoculation) relative to axenically cultured mycelia. 
planta may give an indication as to some of the important molecular processes that are taking place during the three phases of infection. For example, of the 1,947 genes downregulated at $14 \mathrm{dpi}$, genes involved in protein synthesis were significantly overrepresented compared with the rest of the genome $(P$ value $=5.63 \times 10^{-20}$ ), suggesting that fungal growth was restricted during this phase (Gasch 2007; Holstege et al. 1998). In contrast, detoxification genes are overrepresented in the upregulated set $(P$ value $=0.038)$ at this same timepoint. This indicates that plant defenses may be highly active in these initial phases and play a role in minimizing the relative fungal growth, consistent with the decreasing biomass observed during phase 2. Two of these upregulated detoxification genes are homologs of known virulence genes, FGSG_04580 of the Gibberella pulicaris GPABC1 gene (90\% identity), an ATP-binding cassette multidrug-resistance transporter (Fleissner et al. 2002), and FGSG_08721 of Botrytis cinerea BcSOD1 (77\% identity), a $\mathrm{Cu}-\mathrm{Zn}$ superoxide dismutase (Rolke et al. 2004). Both of these genes are being further characterized by the generation of gene knockout mutants for potential pathogenicity and virulence roles.

\section{F. graminearum genes preferentially expressed at individual phases of infection.}

Genes that had a statistically significant change in gene expression in one phase of CR infection compared with the other two phases (axenically cultured mycelia was not included in these calculations) were identified and investigated to discern important biological processes unique to any of the colonization phases. A total of 36 genes were found that had significantly different expression specifically at one of the phases of infection, with 31 showing higher expression at phase 1 and five at phase 2 (Table 2). No gene was significantly preferentially expressed in phase 3 , although the error levels on expression values were larger at this timepoint because three replicates were sampled, as opposed to four replicates used for each of phases 1 and 2. Like the previous gene lists, the majority of these genes showed no homology with any genes of known function. However, among the genes showing homology was a probable glutamine synthetase (FGSG_10264) with significantly higher expression at $2 \mathrm{dpi}$, which is an indicator for nitrogen starvation in many organisms, including filamentous fungi (Palacios et al. 1978; Stephenson et al. 1997). A
A

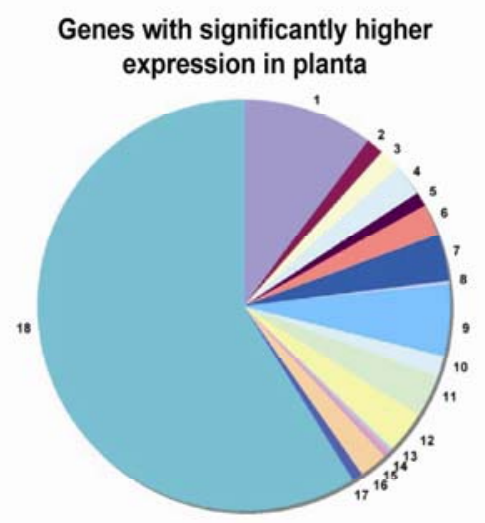

C

Functional Category (MIPS Functional Catalog)

(1) Metabolism

(2) Energy

(3) Cell cycle and DNA processing

(4) Transcription

(5) Protein synthesis

(6) Protein fate (folding, modification, destination)

(7) Protein with binding function or cofactor requirement (structural or catalytic)

(8) Regulation of metabolism and protein function

(9) Cellular transport, transport facilities and transport routes

(10) Cellular communication/signal transduction mechanism

(11) Cell rescue, defence and virulence

(12) Interaction with the environment

(13) Cell fate

(14) Development (Systemic)

(15) Biogenesis of cellular components

(16) Cell type differentiation

(17) Organ differentiation

(18) Unclassified proteins

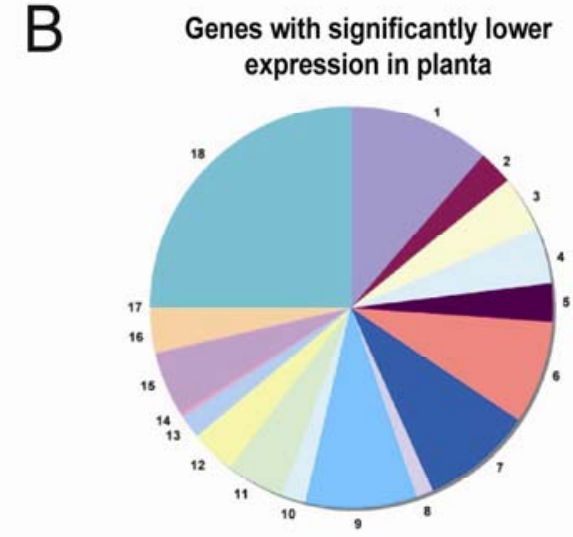

$\begin{array}{rc}\text { Higher Expression } & \text { Lower Expression } \\ 10.23 \% & 11.34 \% \\ 1.55 \% & 2.96 \% \\ 1.59 \% & 4.32 \% \\ 2.36 \% & 4.30 \% \\ 1.27 \% & 3.09 \% \\ 2.36 \% & 8.51 \% \\ 3.73 \% & 8.81 \% \\ 0.36 \% & 1.51 \% \\ 5.46 \% & 8.66 \% \\ 1.73 \% & 2.06 \% \\ 3.32 \% & 4.46 \% \\ 3.27 \% & 3.62 \% \\ 0.18 \% & 2.09 \% \\ 0.45 \% & 0.30 \% \\ 0.18 \% & 5.19 \% \\ 2.27 \% & 3.51 \% \\ 0.91 \% & 0.04 \% \\ 58.75 \% & 25.05 \%\end{array}$

Fig. 4. Fungal genes with significantly altered expression in planta compared with axenically cultured mycelia grouped by their predicted function. A, Genes with significantly higher expression in planta, and $\mathbf{B}$, genes that have significantly lower expression in planta. $\mathbf{C}$, The respective number of genes in each functional group in A and B, given as a percentage of the total number of genes found to have either higher or lower expression, respectively, in planta. 
condition of general nutrient starvation is suggested, because we also observed several other genes with higher expression at 2 dpi with probable roles in lipolysis. This is where lipids are broken down into fatty acids in order to utilize energy reserves. These genes include glycerol kinase (FGSG_03247), enoylcoA hydratase (FGSG_13111), and acetyl-CoA hydrolase (FGSG_08266). A probable mannitol-1-phosphate dehydrogenase (FGSG_12827) also had a higher expression at 2 dpi, suggesting that $F$. graminearum may have been using stored mannitol as a carbohydrate source (Corina and Munday 1971).

\section{Bioinformatic comparison of $\boldsymbol{F}$. graminearum global gene expression patterns during CR and FHB on grasses.}

Fusarium graminearum has the capability of causing head blight and crown rot disease in many grasses worldwide. While both diseases have been studied independently, it is widely hypothesized that the host-pathogen interaction at a molecular level will be similar in both infections, but to date, there has been little research comparing the two diseases. In previous work by Guldener and associates (2006b), the global gene expression of an American Fusarium graminearum isolate (PH-1) during $\mathrm{FHB}$ on barley was analyzed using $F$. graminearum Affymetrix GeneChip. Briefly, barley heads were infected, and samples were taken at 1,2,3, 4, and $6 \mathrm{dpi}$, each sample consisting of three biological replicates. The use of the Affymetrix GeneChip platform with the specified normalizations makes it possible to compare gene expression patterns from independent experiments. Therefore, to gain an overall picture of how similar the global gene expression of $F$. graminearum is during $\mathrm{CR}$ and $\mathrm{FHB}$, sample clustering with bootstrapping was performed using the GeneSpring software. The three CR timepoints from this study and the five FHB timepoints from the previous study were used in this analysis, and the results of this experiment are graphically represented as a condition tree (Fig. 5). In general, the analysis separated the expression patterns of the two diseases and experiments, with all the CR data clustering and the FHB timepoints of 2, 3, 4, and 6 dpi also clustering. However, the results also showed that the 1 dpi FHB sample was most similar to the 2- and 14- dpi CR samples followed by the 35-dpi CR sample and clustered away from the other FHB samples. These results indicate that the infection processes of $F$. graminearum, when causing crown rot and in early stages of head blight, are significantly similar at a molecular level but are different from those associated with later stages of FHB disease development. These comparisons also suggest similarities in the infection-related gene expression patterns of the two different isolates used in these experiments and also a similarity in the processes used by $F$. graminearum to infect wheat and barley, at least at early stages of infection.

In consideration of these results, the analysis of CR and FHB together was taken a step further to identify the genes that show significantly greater expression during both the $\mathrm{CR}$ and FHB disease relative to that of the axenically cultured mycelium reference used in each experiment. A total of 172 genes were identified as upregulated in planta in both diseases (Supplementary Table 2), and 64 of these genes showed homology to genes of known function (Table 3). Genes involved in Ccompound and carbohydrate metabolism were significantly enriched $\left(P\right.$ value $\left.=1.38^{-03}\right)$ and were mostly depolymerases. Of these, 19 are predicted to be extracellular secreted proteins (ProtComp 6.0; Softberry, Inc., Mount Kisco, NY, U.S.A.) and most, if not all, probably act as cell wall-degrading enzymes. Homologs of enzymes that degrade cellulose, pectins, and xylans, as well as two probable cutinases were identified. Depolymerases active against other plant components were also present, with one glucoamylase that would be active against starch and two proteases. This indicates that secreted depolymerases that target polysaccharides, cutin, and protein play an integral part in $F$. graminearum pathogenicity on grasses in both CR and FHB diseases.

Also upregulated in both CR and FHB were two well-known FHB virulence genes, TRI5 (FGSG_03537) (Proctor et al. 1995) and TRI14 (FGSG_03543) (Dyer et al. 2005) from the trichothecene gene cluster, that determine the biosynthesis of the mycotoxin DON. This is consistent with a previous report (Mudge et al. 2006) of DON production during $F$. graminearum $\mathrm{CR}$ disease in wheat and the possible role it may play dur-

Table 1. Functional classes enriched for genes showing upregulated expression during crown rot (CR) compared with that of axenically cultured mycelium ${ }^{\mathrm{a}}$

\begin{tabular}{|c|c|c|c|c|c|}
\hline 2 days postinoculation & $P$-value & 14 days postinoculation & $P$-value & 35 days postinoculation & $P$-value \\
\hline 99 Unclassified proteins & 0 & 99 Unclassified proteins & 0 & 99 Unclassified proteins & 3.7E-04 \\
\hline $\begin{array}{l}\text { 01.01.05.03 Metabolism of urea } \\
\text { (urea cycle) }\end{array}$ & 0.015 & $\begin{array}{l}\text { 01.01.05.03 Metabolism of urea (urea } \\
\text { cycle) }\end{array}$ & 0.019 & $\begin{array}{l}\text { 20.01.07 Amino acid / amino acid } \\
\text { derivitives transport }\end{array}$ & 0.029 \\
\hline $\begin{array}{l}\text { 01.05.03 Polysaccharide } \\
\text { metabolism }\end{array}$ & 0.001 & 01.05.03 Polysaccharide metabolism & $4.9 \mathrm{E}-05$ & $\begin{array}{l}\text { 20.03.02.02.02 Sodium driven } \\
\text { symporter }\end{array}$ & 0.035 \\
\hline 11.06 RNA modification & 0.029 & $\begin{array}{l}\text { 01.01.06.06.01.01 Diaminopimelic } \\
\text { acid pathways }\end{array}$ & 0.025 & $\begin{array}{l}\text { 20.09.18.07 Nonvesicular cellular } \\
\text { import }\end{array}$ & 0.045 \\
\hline $\begin{array}{l}\text { 20.01.03 C-compound and } \\
\text { carbohydrate transport }\end{array}$ & 0.028 & 01.01.11.01.01 Biosynthesis of alanine & 0.012 & 32.05.05.01 Toxins & 0.006 \\
\hline 20.01.27 Drug/toxin transport & 0.034 & 01.01.11.01.02 Degradation of alanine & 0.012 & $\begin{array}{l}\text { 34.01.03.03 Homeostasis of } \\
\text { phosphates }\end{array}$ & 0.048 \\
\hline $\begin{array}{l}\text { 20.03.02 Carrier (electrochemical } \\
\text { potential-driven transport) }\end{array}$ & 0.037 & $\begin{array}{l}\text { 01.01.11.06 Metabolism of the D- } \\
\text { alanine amino acid group }\end{array}$ & 0.012 & $\begin{array}{l}36.20 \text { Plant/fungal specific systemic } \\
\text { sensing and response }\end{array}$ & 0.007 \\
\hline $\begin{array}{l}\text { 20.09.18.07 Nonvesicular cellular } \\
\text { import }\end{array}$ & 0.011 & $\begin{array}{l}\text { 01.20.35.01 Metabolism of } \\
\text { phenylpropanoids }\end{array}$ & 0.009 & $\begin{array}{l}40.01 .05 \text { Growth regulators / } \\
\text { regulation of cell size }\end{array}$ & 0.047 \\
\hline \multirow[t]{7}{*}{$\begin{array}{l}36.20 \text { Plant/fungal specific } \\
\text { systemic sensing and response }\end{array}$} & 0.01 & $\begin{array}{l}01.25 \text { Extracellular polysaccharide } \\
\text { degradation }\end{array}$ & 0.042 & & \\
\hline & & 16.05 Polysaccharide binding & 0.04 & & \\
\hline & & 20.01.27 Drug/toxin transport & 0.026 & & \\
\hline & & 20.03.02.03 Proton driven antiporter & 0.024 & & \\
\hline & & $\begin{array}{l}\text { 20.09.18.07 Nonvesicular cellular } \\
\text { import }\end{array}$ & 0.009 & & \\
\hline & & 32.07 Detoxification & 0.038 & & \\
\hline & & $\begin{array}{l}\text { 36.20 Plant/fungal specific systemic } \\
\text { sensing and response }\end{array}$ & 0.011 & & \\
\hline
\end{tabular}

\footnotetext{
${ }^{a}$ The proportion of genes in each class in the CR upregulated data set was compared to the proportion of genes for each corresponding class across the whole genome. Gene functional categories were assigned using FunCatDB (MIPS) and P-values were calculated using the hypergeometric distribution.
} 
ing $F$. graminearum colonization during $\mathrm{CR}$ of wheat. Another possible toxin biosynthetic gene was also found, NPS8 (FG00042), predicted to encode a seven-module nonribosomal peptide synthetase.

Table 2. Fusarium graminearum genes that are significantly differentially regulated during crown rot $(\mathrm{CR})$

\begin{tabular}{|c|c|}
\hline Gene & Function \\
\hline \multicolumn{2}{|c|}{ Genes that have significantly higher expression at $2 \mathrm{dpi}^{\mathrm{a}}$} \\
\hline FGSG_03970 & Conserved hypothetical protein \\
\hline FGSG_06082 & Conserved hypothetical protein \\
\hline FGSG_07488 & Conserved hypothetical protein \\
\hline Fg4B 43_at & New open reading frame (ORF) \\
\hline FGSG_01943 & Conserved hypothetical protein \\
\hline FGSG_11900 & Conserved hypothetical protein \\
\hline FGSG_08682 & Conserved hypothetical protein \\
\hline FGSG_07863 & Conserved hypothetical protein \\
\hline FGSG_05653 & Related to A. thaliana hyp1 protein \\
\hline FGSG_06682 & Conserved hypothetical protein \\
\hline FGSG_04933 & Conserved hypothetical protein \\
\hline FGSG_03715 & Conserved hypothetical protein \\
\hline FGSG_11296 & Conserved hypothetical protein \\
\hline Fg4A76_at & New ORF \\
\hline FGSG_08266 & Probable acetyl-CoA hydrolase \\
\hline Fg3A549_at & New ORF \\
\hline FGSG_08985 & $\begin{array}{l}\text { Probable ENA5 - Plasma membrane P-type ATPase } \\
\text { involved in } \mathrm{Na}+\text { and } \mathrm{Li}+\text { efflux }\end{array}$ \\
\hline FGSG_10264 & Probable glutamine synthetase \\
\hline FGSG_03247 & Probable GUT1 - glycerol kinase \\
\hline FGSG_12827 & M1PD probable mannitol-1-phosphate dehydrogenase \\
\hline FGSG_08375 & Related to dicarboxylate carrier protein \\
\hline FGSG_00150 & Related to endo-polygalacturonase 6 \\
\hline FGSG_08427 & Probable transcription initiation factor TFIID \\
\hline FGSG_02986 & Conserved hypothetical protein \\
\hline FGSG_02925 & Conserved hypothetical protein \\
\hline $\mathrm{Fg} 4 \mathrm{~A} 2188 \_$at & Probable part of fg 12840 putative protein [EST hit] \\
\hline FGSG_07908 & Reductase \\
\hline FGSG_04288 & Related to $26 \mathrm{~S}$ proteasome subunit RPN4 \\
\hline FGSG_13111 & Related to enoyl-CoA hydratase. \\
\hline FGSG_07052 & Related to krueppel protein. \\
\hline FGSG_11900 & Conserved hypothetical protein \\
\hline \multicolumn{2}{|c|}{ Genes that have significantly higher expression at $14 \mathrm{dpi}^{\mathrm{b}}$} \\
\hline FGSG_10653 & Conserved hypothetical protein \\
\hline FGSG_00729 & Related to nonhistone chromosomal protein \\
\hline FGSG_01161 & Related to phosphatidylinositol-4-kinase \\
\hline FGSG_03041 & Related to alchohol dehydrogenase I -ADH1 \\
\hline FGSG_07213 & $\begin{array}{l}\text { Probable dolichol phosphate-mannose biosynthesis } \\
\text { regulatory protein }\end{array}$ \\
\hline
\end{tabular}

${ }^{\mathrm{a}}$ Genes that are expressed at significantly higher levels at 2 days postinoculation (dpi) than at 14 and 35 dpi.

${ }^{\mathrm{b}}$ Genes that are expressed at significantly higher levels at 14 dpi than at 2 and 35 dpi.
There were also several other secreted proteins listed, such as TOX3 (FGSG_00062), which is related to KP4 killer toxin, and a gene related to a trihydrophobin precursor (FGSG_01831). Also in this list are two genes that are homo$\operatorname{logs}$ of the Blumeria graminis f. sp. hordei Egh16 genes (FGSG_09353 and FGSG_04647) that are thought to be involved in pathogenicity during the early stages of penetration and hyphal formation of many pathogenic fungi (Grell et al. 2003).

\section{DISCUSSION}

The infection process of $F$. graminearum during CR disease of wheat was followed using a combination of biomass estimations and histological analyses. It appeared that colonization of the wheat plant by $F$. graminearum during $\mathrm{CR}$ proceeded in three distinct phases.

Phase 1 was a statistically significant increase in $F$. graminearum biomass in the first two days after inoculation. Confocal imaging of the inoculation point suggested that this initial increase in fungal biomass was due to the germination of spores and superficial hyphal growth on the leaf sheath abaxial surface. Interestingly, during phase 2 there was a large, statistically significant decrease in fungal biomass lasting for at least two weeks. During this period, the fungus was found to have penetrated the outer leaf sheath and to have migrated to the leaf-sheath base, where the adaxial leaf epidermis was colonized with both intracellular and intercellular hyphae. The reduction in fungal biomass during phase 2 suggests that, initially, only a small number of germ tubes successfully penetrated the leaf-sheath tissue and survived, while the hyphae remaining on the sheath surface deplete all available nutrients and subsequently perish. Phase 3 of $F$. graminearum colonization of wheat during CR involves a substantial and statistically significant increase in fungal biomass that correlates with the fungal colonization of the wheat crown parenchyma.

In FHB of wheat, the colonization pathway has been well described (Guenther and Trail 2005; Jansen et al. 2005). Briefly, after inoculation at anthesis, $F$. graminearum hyphae migrate along the epicarp to the space between the lemma and palea, where the epidermis is penetrated. This is followed by the colonization of the rachis, and movement between the florets occurs through the vascular bundles. This highlights the contrasting environments and barriers $F$. graminearum encounters during CR and FHB infections, even though they are diseases of the same host. The colonization pathway of wheat seedling tissue by $F$. graminearum during the three phases of $\mathrm{CR}$ seemed to correspond to specific tissue and developmental

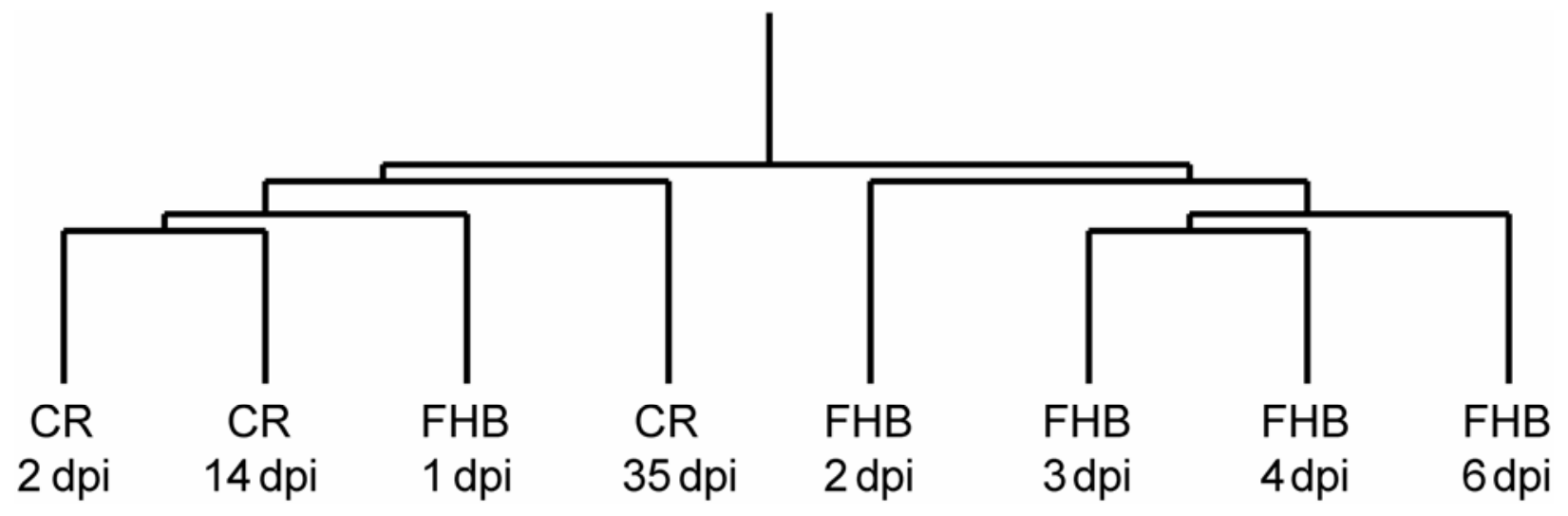

Fig. 5. Condition tree based on the similarity of Fusarium graminearum gene expression between each sample from Fusarium head blight (FHB) on barley (Guldener et al. 2006b) and crown rot (CR) on wheat experiment. The distance between FHB 1 day postinoculation (dpi) and CR 2 and 14 dpi is 0.24 with $100 \%$ bootstrapping confidence from 100 data sets. 
stages of plant growth. During phase 2, F. graminearum mycelia were only observed in leaf sheath 1 below the point of inoculation and, indeed, had reached the base of the sheath below the soil surface. Like other small grain cereals, the growing point of the wheat seedling at this stage of development is below the soil surface and may provide a favorable environment for $F$. graminearum colonization because it is very rich in nutrients. During phases 1 and 2, the wheat seedling shoot is composed of layers of leaf sheaths and emerging leaves with air cavities between each layer. This stratum of physical barriers may restrict lateral penetration of $F$. graminearum into the center of the shoot, thus limiting colonization

Table 3. Fusarium graminearum genes whose expression is significantly upregulated in both crown rot (CR) and Fusarium head blight (FHB) and show homology to known genes

\begin{tabular}{|c|c|c|}
\hline Gene & Description & Possible function \\
\hline FGSG_13319 & Related to transcriptional regulator atrx homolog & Transcriptional regulation \\
\hline FGSG_04114 & Related to adenosine deaminase & RNA metabolism \\
\hline FGSG_05278 & Probable amidophosphoribosyl transferase & RNA metabolism \\
\hline FGSG_01290 & Probable mitochondrial ribosomal protein L2 of the large subunit & RNA metabolism \\
\hline FGSG_12301 & Probable RNA helicase dbp2 (dead box protein) & RNA metabolism \\
\hline FGSG_11064 & Related to glycine-rich RNA-binding protein & RNA metabolism \\
\hline FGSG_10791 & Probable ATP-dependent RNA helicase DHH1 & RNA metabolism \\
\hline FGSG_09733 & Related to 20S proteasome maturation factor & Signal transduction \\
\hline FGSG_06796 & Related to centractin (ARP1) & Signal transduction \\
\hline FGSG_09820 & Related to cysteine dioxygenase type I & Sulphur metabolism \\
\hline FGSG_08126 & Related to alpha glucosidase II beta subunit & Glycoprotein metabolism \\
\hline FGSG_07213 & Probable dolichol phosphate-mannose biosynthesis regulatory protein & Glycoprotein metabolism \\
\hline FGSG_04930 & Related to alpha-mannosidase $1 \mathrm{a}$ & Depolymerase \\
\hline FGSG_02866 & Possible glycosyl hydrolase & Depolymerase \\
\hline FGSG_03143 & Related to glycosyl hydrolase & Depolymerase \\
\hline FGSG_13834 & Related to bromodomain protein BDF1 & Depolymerase \\
\hline FGSG_11066 & Related to beta-mannanase & Depolymerase \\
\hline FGSG_12586 & Related to beta-glucosidase & Depolymerase \\
\hline FGSG_02386 & Probable pectate lyase & Depolymerase \\
\hline FGSG_09291 & Probable pectate lyase 1 & Depolymerase \\
\hline FGSG_03457 & Probable cutinase 1 precursor & Depolymerase \\
\hline FGSG_01570 & Probable cutinase precursor & Depolymerase \\
\hline FGSG_09382 & Probable alkaline protease (oryzin). & Depolymerase \\
\hline FGD107-180 & Related to xylanase (c-terminal fragment) & Depolymerase \\
\hline FGSG_04768 & Related to endo-1,3-beta-glucanase & Depolymerase \\
\hline FGSG_06445 & Probable endo-1,4-beta-xylanase & Depolymerase \\
\hline FGSG_12047 & Probable endo-1,4-beta-xylanase A precursor & Depolymerase \\
\hline FGSG_00150 & Probable NADP-dependent oxidoreductase P2 & Depolymerase \\
\hline FGSG_06397 & Related to endoglucanase B & Depolymerase \\
\hline FGSG_11488 & Related to cellulose binding protein CEL & Depolymerase \\
\hline FGSG_03632 & Related to cellulose binding protein CEL1 & Depolymerase \\
\hline FGSG_03968 & Related to cellulose binding protein CEL1 & Depolymerase \\
\hline FGSG_03194 & Probable endopolygalacturonase & Depolymerase \\
\hline FGSG_02202 & Probable endoglucanase IV precursor & Depolymerase \\
\hline FGSG_03695 & Related to endoglucanase IV precursor & Depolymerase \\
\hline FGSG_03315 & Related to endopeptidase $\mathrm{K}$ & Depolymerase \\
\hline FGSG_04704 & Related to glucoamylase precursor & Depolymerase \\
\hline FGSG_09353 & Related to gEgh 16 protein & Pathogenicity associated \\
\hline FGSG_04647 & Probable gEgh 16 protein & Pathogenicity associated \\
\hline FGSG_07832 & Related to $\mathrm{CCC} 1$ protein (involved in calcium homeostasis) & Transporter \\
\hline FGSG_04580 & Probable ABC1 transport protein & Transporter \\
\hline FGSG_12335 & Related to DHA14-like major facilitator efflux transporter (MFS transporter) & Transporter \\
\hline FGSG_03646 & Related to nicotinamide mononucleotide permease & Transporter \\
\hline FGSG_02580 & Related to maltose permease (MalP & Transporter \\
\hline FGSG_03107 & Related to high affinity methionine permease & Transporter \\
\hline FGSG_07227 & Probable isp 4 protein & Transporter \\
\hline FGSG_06331 & Related to zinc transporter & Transporter \\
\hline FGSG_08172 & Related to $\mathrm{Cu}$-binding metallothionein & Oxidative stress \\
\hline FGSG_07765 & Related to isotrichodermin C-15 hydroxylase (cytochrome P-450 monooxygenase CYP65A1) & Oxidative stress \\
\hline FGSG_02792 & Related to NAD $(\mathrm{P}) \mathrm{H}$-dependent oxidoreductase & Oxidative stress \\
\hline FGSG_12643 & Probable sterol glucosyltransferase & Lipid metabolism \\
\hline FGSG_08613 & Probable OPI3 - methylene-fatty-acyl-phospholipid synthase & Lipid metabolism \\
\hline FGSG_00062 & TOX 3 - related to KP4 killer toxin & Small secreted protein \\
\hline FGSG_08081 & Related to gibberellin 20-oxidase & $\begin{array}{l}\text { Gibberellin biosynthesis/ } \\
\text { oxidative stress }\end{array}$ \\
\hline FG00042 & NPS8 nonribosomal peptide synthetase & Toxin biosynthesis \\
\hline FGSG_03537 & TRI5 trichodiene synthase & Toxin biosynthesis \\
\hline FGSG_03543 & TRI14 trichothecene biosynthesis gene & Toxin biosynthesis \\
\hline FGSG_00656 & Related to F1F0-ATP synthase subunit G & Housekeeping \\
\hline FGSG_11095 & Related a to carbonic anhydrase & Housekeeping \\
\hline FGSG_05483 & Related to ARG8- acetylornithine aminotransferase & Housekeeping \\
\hline FGSG_11897 & Probable UTR 1 protein, associated with ferric reductase activity & Housekeeping \\
\hline FGSG_00642 & Related to spore coat protein SP96 precursor & Cell Surface Protein \\
\hline FGSG_01831 & Related to trihydrophobin precursor & Cell Surface Protein \\
\hline FGSG_00449 & Related to WD repeat protein IEF SSP 9502 & Protein interactions \\
\hline
\end{tabular}


to the outer leaf sheath. Stem elongation commences during phase 3 , and the elongating stem (internode) tissue provides continuity throughout the shoot, which may permit more rapid colonization of stem parenchyma. This may then enable $F$. graminearum colonization up the stem via the central stem lumen and parenchyma, toward the developing inflorescence, seen previously in mature wheat plants (Mudge et al. 2006). In the study by Mudge and associates (2006), F. graminearum hyphae were visualized in the stem lumen at the nodes immediately above the crown at around 56 dpi.

The delay in visible symptoms during the CR infection may be partly explained by the delayed production of DON. Studies have shown that although genes involved in the biosynthesis of DON are expressed early in CR infection, significant accumulation of the mycotoxin does not occur until $28 \mathrm{dpi}$ (Mudge et al. 2006). It has been demonstrated that DON induces cell death in wheat, most probably by triggering the production of reactive oxygen species (Desmond et al. 2008) and ultimately leading to browning. The accumulation of DON in the described study coincides with the necrotrophic phase 3 of $\mathrm{CR}$ infection in this study, in which we see necrosis of the wheat tissue and a significant increase in fungal biomass.

Global $F$. graminearum gene expression analysis during CR infection of wheat found that $59 \%$ of significantly upregulated genes in planta were unclassified by homology in contrast to only $25 \%$ of all significantly downregulated genes, as compared with axenically cultured mycelia. This suggests that our understanding of the genes that contribute to infection is limited. A similar overrepresentation of unclassified genes was seen during the germination of conidia (Seong et al. 2008). It is understood that the cultured mycelia sample used represents a reference for only a single growth condition and phase of growth and does not comprehensively represent all genes expressed during in vitro culture.

During phase 1, genes encoding enzymes involved in the remobilization of stored nutrients as well as nutrient acquisition were frequently observed, and gene expression data suggested the processes of lipolysis, fatty acid $\beta$-oxidation, ammonium assimilation, and stored mannitol utilization were probably active. This would be expected for the initial stages of infection on the leaf-sheath surface, which is poor in nutrients. During phase 2, the reduction of biomass and upregulation of detoxification genes suggests that the pathogen is attempting to overcome host defenses. These early stages of the infection, therefore, represent the greatest opportunity for control of $\mathrm{CR}$ disease by preventing the extensive colonization, formation of necrotic tissue, and accumulation of DON observed at phase 3 . In this study, we show that $F$. graminearum gene expression in the very early stages of FHB infection is significantly similar to those of CR. This suggests that spore adhesion, germination, penetration, and subverting initial plant defenses are comparable at a molecular level for both types of $F$. graminearum disease. Indeed, we see a number of extracellular secreted depolymerases, detoxification, and stress related genes upregulated in both CR and FHB. This also means that developing a control for CR disease may also be effective in arresting early stages of infection of FHB and vice versa.

In summary, this study gives an overview of the $F$. graminearum CR colonization pathway. We have identified three distinct phases of infection, in which fungal proliferation seems to be temporarily repressed in phase 2 before the disease really takes hold in phase 3 . We have determined which tissues of the wheat plant are colonized at each phase of infection and which $F$. graminearum genes are expressed in association with pathogenicity during the infection stages. The current study serves as an excellent platform for future work identifying which genes are essential for $F$. graminearum pathogenicity during CR infection of wheat and also how host resistance may affect the stages of infection.

\section{MATERIALS AND METHODS}

Fungal strain and inoculum preparation.

For the purpose of this report the anamorph term F. graminearum will be used to describe the fungus. All experiments described here were conducted with the Australian F. graminearum isolate CS3005 (Akinsanmi et al. 2006). Macroconidia for inoculation were produced by inoculating $20 \mathrm{~cm}$ SNA (Spezieller Nahrstoffarmer agar) plates with a half strength potato dextrose agar (PDA) plug colonized with CS3005, then incubating at room temperature for 7 days. Spores were collected by adding $10 \mathrm{ml}$ of sterile water, scraping the agar surface with a scalpel, and filtering the spore suspension through Mira cloth onto a $40 \mathrm{~cm}$ SNA plate and then incubating at room temperature for 7 days. Spores were washed off the SNA surface again with sterile water and the spore concentration was adjusted to $1 \times 10^{6}$ spores per milliliter in distilled water, and used fresh for all inoculations.

\section{Plant growth, inoculation and harvesting technique.}

For all experiments the CR and FHB susceptible bread wheat cultivar Kennedy was used. All seedlings were grown in an environmentally controlled glasshouse with day-time conditions of $24^{\circ} \mathrm{C}$ temperature with $60 \%$ humidity and night-time conditions of $15^{\circ} \mathrm{C}$ with $90 \%$ humidity. Trays of plastic seedling punnets $(5 \times 5 \mathrm{~cm}$ per punnet, 30 punnets to a tray) were filled with sterile soil mix comprising $50 \%$ sand and $50 \%$ peat ( vol/vol), and two seeds were planted in each punnet. Seedlings were grown and inoculated 14 days after planting at the base of the shoot as described (Mitter et al. 2006). All seedlings were harvested and the shoot tissue from the crown to leaf 1 was excised with a pair of sharp scissors and used as a source of genetic material.

\section{DNA extractions and $F$. graminearum biomass estimations.}

Wheat seedlings were inoculated with $F$. graminearum macroconidia and harvested at $0,0.5,1,2,14,28,35,42$, and 49 dpi. For each timepoint three biological replicates were taken in parallel. Each biological replicate comprised a pool of 18 shoot bases. Shoot bases were ground in liquid nitrogen with a mortar and pestle and genomic DNA was extracted using a QIAGEN DNeasy plant mini kit according to the manufacturer's instructions. DNA was eluted into $100 \mu \mathrm{l}$ of sterile water and stored at $-20^{\circ} \mathrm{C}$ until needed. F. graminearum biomass was estimated indirectly using real-time quantitative PCR (RT-qPCR). PCR was performed in a total volume of $10 \mu \mathrm{l}$ containing $5 \mu \mathrm{l}$ of SYBR GREEN PCR master mix (Applied Biosystems, Scoresy, Victoria, Australia), 1 $\mu \mathrm{l}$ of a $3-\mu \mathrm{M}$ mix of forward and reverse primers and $4 \mu \mathrm{l}$ of DNA diluted 1:10 in water. Cycling conditions used were a $15 \mathrm{~s}$ denaturation step at $95^{\circ} \mathrm{C}$ then an anneal/extension step of $1 \mathrm{~min}$ at $60^{\circ} \mathrm{C}$ repeated 40 times followed by a final denaturation step. For detecting $F$. graminearum and wheat DNA, fungal 18S (Mudge et al. 2006) and wheat actin binding protein (U58278) primers (forward 5'-CGCGAGGAACAAGAT GCTGTA-3'-3' and reverse 5'-CACGTCGATCTGCACGCC$3^{\prime}$ ), were used. Estimation of $F$. graminearum biomass was calculated according to the following equation, in which Ef is the PCR amplification efficiency and $\mathrm{Ct}$ is the crossing threshold.

$$
\text { Rel Biomass }=\frac{\mathrm{Ef}_{\text {Fungal }}-C t}{\mathrm{Ef}_{\text {Plant }}-C t}
$$


PCR amplification efficiencies were calculated by using the program LinRegPCR 7.5 (Ramakers et al. 2003).

\section{Microscopic analysis of $F$. graminearum during CR infection.}

Wheat plants were inoculated with $F$. graminearum macroconidia and were sampled at 2,14, and 35 dpi. Live samples were hand sectioned at the base of the shoot and were stained with $2 \mu \mathrm{M}$ WGA-Alexa Fluor 488 (Invitrogen, Carlsbad, CA, U.S.A.) and toluidine blue for up to $2 \mathrm{~h}$. Sections were then analyzed with a light microscope, Leica SP2 confocal laser scanning microscope (Leica Microsystems, Wetzlar, Germany), and a Zeiss LSM-510 META inverted confocal microscope. Excitation wavelengths used were 405 and $488 \mathrm{~nm}$, with capture between 420 to $475 \mathrm{~nm}$ and 500 to $527 \mathrm{~nm}$, respectively.

\section{RNA extraction and microarray hybridization.}

Wheat seedlings were inoculated and harvested as described above at 2, 14, and 35 dpi. For each timepoint, four biological replicate samples were taken in parallel, except for $35 \mathrm{dpi}$, for which three were taken, and each biological replicate was a pool of 18 shoot bases. Shoot bases were ground in liquid nitrogen with a mortar and pestle, and total RNA was extracted using a QIAGEN RNeasy plant mini kit (Qiagen, Hilden, Germany) according to the manufacturer's instructions, using RLT buffer and including the optional on-column DNase I digestion. Mycelial samples were grown in a 96-well plate in $100 \mu \mathrm{l}$ of defined media per well. Spores were inoculated into the media at a final concentration of $1 \times 10^{4}$ spores per milliliter. The media contained $88 \mathrm{mM}$ sucrose, $5 \mathrm{mM}$ glutamine, $7.3 \mathrm{mM}$ $\mathrm{KH}_{2} \mathrm{PO}_{4}, 2 \mathrm{mM} \mathrm{MgSO} \cdot 7 \mathrm{H}_{2} \mathrm{O}, 6.7 \mathrm{mM} \mathrm{KCl}, 36 \mu \mathrm{MeSO}_{4} \cdot 7$ $\mathrm{H}_{2} \mathrm{O}, 47 \mu \mathrm{M}$ citric acid, $32 \mu \mathrm{M} \mathrm{ZnSO}_{4} \cdot 7 \mathrm{H}_{2} \mathrm{O}, 1.8 \mu \mathrm{M}$ $\mathrm{CuSO}_{4} \cdot 5 \mathrm{H}_{2} \mathrm{O}, 0.5 \mu \mathrm{M} \mathrm{MnSO}_{4} \cdot \mathrm{H}_{2} \mathrm{O}, 1.5 \mu \mathrm{M} \mathrm{H} \mathrm{BO}_{3}, 0.4 \mu \mathrm{M}$ $\mathrm{NaMoO}_{4} \cdot 2 \quad \mathrm{H}_{2} \mathrm{O}, 0.03 \%$ Phytagel adjusted to $\mathrm{pH} 6.5$ with $\mathrm{NaOH}$ (Correll et al. 1987).

Labeling and hybridization of the total RNA was carried out according to the expression analysis technical manual (Affymetrix) at the Australian Genome Research Facility (Melbourne), using the $F$. graminearum Affymetrix GeneChip (Guldener et al. 2006b).

\section{Analysis of global gene expression data.}

Expression data was analyzed by importing CEL files into GeneSpring GX 7.3 (Silicon Genetics; Agilent Technologies, Palo Alto, CA, U.S.A.). Data for each chip was normalized to the median, assessed for signal quality by condition-tree clustering, and filtered on raw signal intensity of greater than 100 , to determine whether gene expression was present or absent. The number of genes up- and downregulated in planta was calculated by comparing normalized expression values with axenically cultured mycelia GeneChip data of the same $F$. graminearum isolate. To do this, a Welch $t$-test with a $P$ value of 0.01 and a Benjamini and Hochberg false-discovery multiple-testing correction was performed between the average of the replicate samples of axenically cultured mycelia and each of the in planta timepoints tested $(2,14$, and 35 dpi). Because sufficient biological replication was used in this experiment, genes were not subjected to a fold-change threshold cutoff, any change in expression was deemed meaningful as long as it was statistically significant. $F$. graminearum genes upregulated during FHB of barley were identified using the same calculations as in CR, using the CEL files made available at the PLEXdb database (Guldener et al. 2006b). F. graminearum grown in complete medium (Guldener et al. 2006b) was used as the axenically cultured mycelia reference for all FHB calculations. The number of genes that showed significant differential expression in planta was calculated the same way, using the Welch $t$-test between the different CR in planta samples. To test for similarities between CR and FHB timepoints, all samples from the FHB barley experiment and all samples from the current experiment were clustered according to their global gene expression. These results were presented in a condition tree that was created using a Pearson correlation similarity measure with bootstrapping of 100 data sets, an average linkage clustering algorithm and similar branches were merged with a separation ratio of 1 and a minimum distance of 0.001 . Gene functional categorization was determined using FunCatDB, with a $P$ value calculated for each functional category within a list of genes to determine if that category was statistically enriched. This $P$ value was calculated using the hypergeometric distribution as a cumulative probability of each single category, drawing from the population of total genes in that category found in the genome as a whole (Guldener et al. 2006a). Limitations of the software result in very small $P$ values being reported as 0 and those close to 1 reported as 1 .

\section{ACKNOWLEDGMENTS}

We thank U. Güldener (Institute of Bioinformatics and Systems Biology, German Research Center for Environmental Health) for assistance with statistical analysis of gene classes using the FunCatDB. We also thank K. Kazan and L. Thatcher for critically reading the manuscript. A. L. Munn acknowledges funding from the National Health and Medical Research Council (project grant 252750) and the Queensland State Government.

\section{LITERATURE CITED}

Akinsanmi, O. A., Backhouse, D., Simpfendorfer, S., and Chakraborty, S. 2006. Genetic diversity of Australian Fusarium graminearum and $F$. pseudograminearum. Plant Pathol. 55:494-504.

Burgess, L. 2005. Intermediate hosts and the management of crown rot and head blight. Pages 34-36 in: Annual Report of GRDC strategic Initiative on Crown Rot, Common Root Rot and Fusarium Head Blight. Grains Research and Development Corporation. Kingston, Australia

Corina, D. L., and Munday, K. A. 1971. Studies on polyol function in Aspergillus-Clavatus-Role for mannitol and ribitol. J. Gen. Microbiol. 69:221-227.

Correll, J. C., Klittich, C. J. R., and Leslie, J. F. 1987. Nitrate nonutilizing mutants of Fusarium oxysporum and their use in vegetative compatibility tests. Phytopathology 77:1640-1646.

Cuomo, C. A., Gueldener, U., Xu, J. R., Trail, F., Turgeon, B. G., Di Pietro, A., Walton, J. D., Ma, L. J., Baker, S. E., Rep, M., Adam, G., Antoniw, J., Baldwin, T., Calvo, S., Chang, Y. L., DeCaprio, D., Gale, L. R., Gnerre, S., Goswami, R. S., Hammond-Kosack, K., Harris, L. J., Hilburn, K., Kennell, J. C., Kroken, S., Magnuson, J. K., Mannhaupt, G., Mauceli, E., Mewes, H. W., Mitterbauer, R., Muehlbauer, G., Munsterkotter, M., Nelson, D., O’Donnell, K., Ouellet, T., Qi, W. H., Quesneville, H., Roncero, M. I. G., Seong, K. Y., Tetko, I. V., Urban, M., Waalwijk, C., Ward, T. J., Yao, J. Q., Birren, B. W., and Kistler, H. C. 2007. The Fusarium graminearum genome reveals a link between localized polymorphism and pathogen specialization. Science 317:1400-1402.

Desmond, O. J., Manners, J. M., Stephens, A. E., Maclean, D. J., Schenk, P. M., Gardiner, D. M., Munn, A., and Kazan, K. 2008. The Fusarium mycotoxin deoxynivalenol elicits hydrogen peroxide production, programmed cell death and defence responses in wheat. Mol. Plant Pathol. 9:435-445.

Dyer, R. B., Plattner, R. D., Kendra, D. F., and Brown, D. W. 2005. Fusarium graminearum TRI14 is required for high virulence and DON production on wheat but not for DON synthesis in vitro. J. Agric. Food Chem. 53:9281-9287.

Fleissner, A., Sopalla, C., and Weltring, K. M. 2002. An ATP-binding cassette multidrug-resistance transporter is necessary for tolerance of $\mathrm{Gib}$ berella pulicaris to phytoalexins and virulence on potato tubers. Mol. Plant-Microbe Interact. 15:102-108.

Gasch, A. P. 2007. Comparative genomics of the environmental stress response in ascomycete fungi. Yeast 24:961-976.

Goswami, R. S., and Kistler, H. C. 2004. Heading for disaster: Fusarium graminearum on cereal crops. Mol. Plant Pathol. 5:515-525.

Grell, M. N., Mouritzen, P., and Giese, H. 2003. A Blumeria graminis gene family encoding proteins with a $\mathrm{C}$-terminal variable region with 
homologues in pathogenic fungi. Gene 311:181-192.

Guenther, J. C., and Trail, F. 2005. The development and differentiation of Gibberella zeae (anamorph: Fusarium graminearum) during colonization of wheat. Mycologia 97:229-237.

Guldener, U., Mannhaupt, G., Munsterkotter, M., Haase, D., Oesterheld, M., Stumpflen, V., Mewes, H. W., and Adam, G. 2006a. FGDB: A comprehensive fungal genome resource on the plant pathogen Fusarium graminearum. Nucleic Acids Res. 34:D456-458.

Guldener, U., Seong, K. Y., Boddu, J., Cho, S., Trail, F., Xu, J. R., Adam, G., Mewes, H. W., Muehlbauer, G. J., and Kistler, H. C. 2006b. Development of a Fusarium graminearum Affymetrix GeneChip for profiling fungal gene expression in vitro and in planta. Fungal Genet. Biol. 43:316-325.

Holstege, F. C. P., Jennings, E. G., Wyrick, J. J., Lee, T. I., Hengartner, C. J., Green, M. R., Golub, T. R., Lander, E. S., and Young, R. A. 1998. Dissecting the regulatory circuitry of a eukaryotic genome. Cell 95:717-728.

Hou, Z., Xue, C., Peng, Y., Katan, T., Kistler, H. C., and Xu, J.-R. 2002. A mitogen-activated protein kinase gene $(M G V 1)$ in Fusarium graminearum is required for female fertility, heterokaryon formation, and plant infection. Mol. Plant-Microbe Interact. 15:1119-1127.

Jackowiak, H., Packa, D., Wiwart, M., and Perkowski, J. 2005. Scanning electron microscopy of Fusarium damaged kernels of spring wheat. International J. Food Microbiol. 98:113-123.

Jansen, C., von Wettstein, D., Schafer, W., Kogel, K. H., Felk, A., and Maier, F. J. 2005. Infection patterns in barley and wheat spikes inoculated with wild-type and trichodiene synthase gene disrupted Fusarium graminearum. Proc. Natl. Acad. Sci. U.S.A. 102:16892-16897.

Jenczmionka, N. J., Maier, F. J., Losch, A. P., and Schafer, W. 2003. Mating, conidiation and pathogenicity of Fusarium graminearum, the main causal agent of the head-blight disease of wheat, are regulated by the MAP kinase gpmk1. Curr. Gen. 43:87-95.

Jeon, J., Park, S. Y., Chi, M. H., Choi, J., Park, J., Rho, H. S., Kim, S., Goh, J., Yoo, S., Choi, J., Park, J. Y., Yi, M., Yang, S., Kwon, M. J., Han, S. S., Kim, B. R., Khang, C. H., Park, B., Lim, S. E., Jung, K., Kong, S., Karunakaran, M., Oh, H. S., Kim, H., Kim, S., Park, J., Kang, S., Choi, W. B., Kang, S., and Lee, Y. H. 2007. Genome-wide functional analysis of pathogenicity genes in the rice blast fungus. Nat. Genet. 39:561-565.

Kruger, W. M., Pritsch, C., Chao, S., and Muehlbauer, G. J. 2002. Functional and comparative bioinformatic analysis of expressed genes from wheat spikes infected with Fusarium graminearum. Mol. PlantMicrobe Interact. 15:445-455.

McDonald, T., Brown, D., Keller, N. P., and Hammond, T. M. 2005. RNA silencing of mycotoxin production in Aspergillus and Fusarium species. Mol. Plant-Microbe Interact. 18:539-545.

Mitter, V., Zhang, M. C., Liu, C. J., Ghosh, R., Ghosh, M., and Chakraborty, S. 2006. A high-throughput glasshouse bioassay to detect crown rot resistance in wheat germplasm. Plant Pathol. 55:433-441.

Mudge, A. M., Dill-Macky, R., Dong, Y. H., Gardiner, D. M., White, R. G., and Manners, J. M. 2006. A role for the mycotoxin deoxynivalenol in stem colonisation during crown rot disease of wheat caused by Fusarium graminearum and Fusarium pseudograminearum. Physiol. Mol.
Plant Pathol. 69:73-85.

Palacios, R., Sanchez, F., Espin, G., and Mora, J. 1978. Regulation of glutamine-synthetase synthesis and specific messenger-Rna levels in Neurospora-Crassa. Fed. Proc. 37:1430-1430.

Paper, J. M., Scott-Craig, J. S., Adhikari, N. D., Cuom, C. A., and Walton, J. D. 2007. Comparative proteomics of extracellular proteins in vitro and in planta from the pathogenic fungus Fusarium graminearum. Proteomics 7:3171-3183.

Proctor, R. H., Hohn, T. M., and McCormick, S. P. 1995. Reduced virulence of Gibberella-Zeae caused by disruption of a trichothecene toxin biosynthetic gene. Mol. Plant-Microbe Interact. 8:593-601.

Proctor, R. H., Hohn, T. M., and McCormick, S. P. 1997. Restoration of wild-type virulence to Tri5 disruption mutants of Gibberella zeae via gene reversion and mutant complementation. Microbiol.-UK 143:25832591.

Ramakers, C., Ruijter, J. M., Deprez, R. H. L., and Moorman, A. F. M. 2003. Assumption-free analysis of quantitative real-time polymerase chain reaction (PCR) data. Neurosci. Lett. 339:62-66.

Rolke, Y., Liu, S., Quidde, T., Williamson, B., Schouten, A., Weltring, K.M., Siewers, V., Tenberge, K. B., Tudzynski, B., and Tudzynski, P. 2004. Functional analysis of $\mathrm{H} 2 \mathrm{O} 2$-generating systems in Botrytis cinerea: The major $\mathrm{Cu}-\mathrm{Zn}$-superoxide dismutase (BCSOD1) contributes to virulence on French bean, whereas a glucose oxidase (BCGOD1) is dispensable. Mol. Plant Pathol. 5:17-27.

Seong, K. Y., Zhao, X., Xu, J. R., Guldener, U., and Kistler, H. C. 2008. Conidial germination in the filamentous fungus Fusarium graminearum. Fungal Genet. Biol. 45:389-399.

Smiley, R. W., Gourlie, J. A., Easley, S. A., Patterson, L. M., and Whittaker, R. G. 2005. Crop damage estimates for crown rot of wheat and barley in the Pacific Northwest. Plant Dis. 89:595-604.

Southwell, R. J., Moore, K. J., Manning, W., and Hayman, P. T. 2003. An outbreak of Fusarium head blight of durum wheat on the Liverpool Plains in northern New South Wales in 1999. Australas. Plant Pathol. 32:465-471.

Stephenson, S. A., Green, J. R., Manners, J. M., and Maclean, D. J. 1997. Cloning and characterisation of glutamine synthetase from Colletotrichum gloeosporioides and demonstration of elevated expression during pathogenesis on Stylosanthes guianensis. Curr. Genet. 31:447-454.

Trail, F., Xu, J. R., San Miguel, P., Halgren, R. G., and Kistler, H. C. 2003. Analysis of expressed sequence tags from Gibberella zeae (anamorph Fusarium graminearum). Fungal Genet. Biol. 38:187-197.

Urban, M., Mott, E., Farley, T., and Hammond-Kosack, K. 2003. The Fusarium graminearum MAP1 gene is essential for pathogenicity and development of perithecia. Mol. Plant Pathol. 4:347-359.

\section{AUTHOR-RECOMMENDED INTERNET RESOURCES}

PLEXdb database: www.plexdb.org

MIPS FunCatDB database:

mips.gsf.de/cgi-bin/proj/funcatDB/search_advanced.pl?gene=2 